\title{
ADVANCES IN UNDERSTANDING THE MODE OF ACTION OF MBT FUNGICIDE USED IN WOOD PROTECTION
}

\author{
T. SINGH ${ }^{1}$, R. WAKELING ${ }^{1}$, B. KREBER ${ }^{1}$, M.V. JASPERS ${ }^{2}$ \\ and A. STEWART ${ }^{2}$ \\ ${ }^{1}$ Manufacturing Technologies, Forest Research, Rotorua \\ ${ }^{2}$ Soil, Plant \& Ecological Sciences Division, P.O. Box 84, Lincoln University \\ Corresponding author: tripti.singh@forestresearch.co.nz
}

\begin{abstract}
Interactions between methylene bisthiocyanate (MBT) and common wood degrading fungi of Pinus radiata were investigated. The minimum inhibitory concentration (MIC) of MBT was determined in yeast-malt liquid medium and on radiata pine. Higher treatment concentrations of MBT were required to control fungal growth on wood than in liquid culture, irrespective of the test fungus used. There were significant differences between the test fungi for MIC levels of MBT on dip-treated wood with the highest degree of tolerance observed for Trichoderma viride $(\mathrm{MIC} \geq 0.64 \% \mathrm{w} / \mathrm{v})$. Further experiments suggested that vapour action and diffusibility both contributed to the fungitoxicity of MBT.

Keywords: fungicide, methylene bisthiocyanate, Pinus radiata, wood inhabiting fungi.
\end{abstract}

\section{INTRODUCTION}

Sapwood of unseasoned radiata pine (Pinus radiata D. Don) is highly susceptible to attack from a wide range of wood degrading fungi, resulting in a downgrading of the wood's value. To control fungal degradation in unseasoned logs and sawn lumber, antisapstain treatments have traditionally been applied to form an envelope of chemical at the wood surface (Hedley et al. 1979). However, to keep radiata pine logs free from fungal degradation in the New Zealand summer, antisapstain treatments must be applied shortly (<24 h) after tree felling (Eden et al. 1997); this is often not practical. Without early treatment, logs could contain established fungal infections at the time of antisapstain treatment (Wakeling et al. 2000). Today, antisapstain technology containing a mobile fungicide, methylene bisthiocyanate (MBT), is available for satisfactory protection of logs from fungal degradation providing no more than 3-4 days elapses from felling to the time of treatment (Wakeling et al. 2000).

Laboratory and field studies conducted at Forest Research, Rotorua, New Zealand, suggest that MBT is able to arrest fungal pre-infection (Eden et al. 1999b; Wakeling et al. 2000). This is believed to be due to the ability of MBT to migrate in green wood (Williams et al. 1985). This paper reports on further laboratory studies, which aim to advance our current understanding of the mode of action of MBT against wood inhabiting fungi.

\section{METHODS}

Establishing minimum inhibitory concentrations of MBT

Threshold levels (minimum inhibitory concentration, MIC) of the fungicide methylene bisthiocyanate (MBT) were determined against Ophiostoma floccosum Mathiesen isolate 925, Leptographium procerum (Kendrick) M.J. Wingfield isolate 281, Sphaeropsis sapinea (Fr.:Fr.) Dyko and Sutton isolate 2/94, and Trichoderma viride Pers:Fr. isolate $8 / 90$. Spores or hyphal fragments of each fungus were cultured in liquid yeast-malt nutrient medium amended with different concentrations of MBT, ranging from 0.00001 
to 0.0016 percent weight/volume (\%w/v). After 12 days of incubation at $25^{\circ} \mathrm{C}$ in the dark, the biomass produced by each fungus was recorded and MIC value determined.

In a second experiment, MIC values were determined on radiata pine wafers $(50 \times 35 \times 7 \mathrm{~mm})$. Fungal inoculum was prepared $\left(1 \times 10^{5}\right.$ spores or hyphal fragments/ $\mathrm{ml}$ ) and wafers were given a $10 \mathrm{~s}$ agitated dip in inoculum followed by $10 \mathrm{~s} \mathrm{dip-}$ treatment in a range of MBT concentrations $(0.02,0.04,0.08,0.16,0.32$ and $0.64 \% \mathrm{w} / \mathrm{v})$. Wafers were incubated at room temperature inside covered plastic bins and fungal growth assessed weekly over 5 weeks using a rating scale based upon the \% cover of fungal growth over the surfaces of the wood wafers (Table 1).

TABLE 1: Rating system used to quantify fungal growth on radiata pine wafers.

\begin{tabular}{ccc}
\hline Rating & Surface Cover $(\%)$ & MSC $(\%)^{1}$ \\
\hline 0 & 0 (no growth) & 0 \\
1 & $1-5$ & 3.0 \\
2 & $6-25$ & 15.5 \\
3 & $26-50$ & 38.0 \\
4 & $51-75$ & 63.0 \\
5 & $76-100$ & 88.0
\end{tabular}

${ }^{1}$ Mid-range surface cover (MSC) value of fungal growth.

Evaluating the mode of action of MBT against two wood inhabiting fungi

A dual wood wafer assay was used in two separate experiments to evaluate the fungitoxicity of MBT on propagules (spores and/or fragments) of $O$. floccosum and S. sapinea.

The sensitivity of fresh propagules of fungus to MBT treated wood was examined in Experiment 1 . Wood wafers were given a $10 \mathrm{~s}$ agitated dip in fungal inoculum $\left(1 \times 10^{5}\right.$ spores or hyphal fragments $/ \mathrm{ml}$ ). Additional wafers were treated with fungicide at different concentrations $(0.02,0.04,0.08,0.16,0.32$ and $0.64 \% \mathrm{w} / \mathrm{v})$. Two wafers, one inoculated (Wafer 1) and the other fungicide treated (Wafer 2) were held together with a rubber band. Each wafer assembly was placed on plastic rods in a clear plastic container $(90 \mathrm{~mm}$ diameter x $60 \mathrm{~mm}$ deep) lined with moistened filter paper and vermiculite. The containers were closed with a lid and incubated in the dark at $25^{\circ} \mathrm{C}$. Three replicates were set up for each fungus/fungicide concentration with six replicates containing no fungicide to serve as controls. Four faces (A, B, C and D) of the two wafers were assessed. Wafer 1 (on the top, during assembly) represented faces $A$ (outer) and $B$ (inner), whereas wafer 2 represented faces $\mathrm{C}$ (inner) and D (outer). Extent of fungal growth on the faces of the two wafers contained in each assembly was visually assessed each week for 5 weeks using the rating system outlined in Table 1. After 5 weeks, an average mid range surface cover (MSC \%) was calculated for each fungus tested and plotted against MBT concentrations.

The effect of MBT vapour on fungal propagules was examined in Experiment 2. Using the protocol of Experiment 1, aluminum foil $(60 \times 45 \mathrm{~mm})$ was placed between the two wafers prior to assembly. This was done to prevent direct diffusion of MBT occurring between the two wafers; therefore any inhibition of fungal growth on the faces of untreated, but inoculated, wafers would most likely be due to the activity of vapour from the treated wafer. Fungal growth was monitored weekly for 5 weeks on face A, without opening the container.

Statistical analysis of all experimental data was done using the GLM procedure in SAS-STAT. Analysis of variance was followed by comparison of means for significant effect using LSD. Differences were considered to be significant at $\mathrm{P}<0.05$. 


\section{RESULTS}

Establishing minimum inhibitory concentrations of MBT

For all fungi, in liquid medium, biomass decreased as the concentration of MBT increased until growth stopped at the level corresponding to the MIC range. Of the four fungi tested, $T$. viride showed a significantly higher degree of tolerance $(\mathrm{P}<0.05)$ towards MBT (Table 2). MBT was fungicidal as the test fungi were killed when exposed to levels corresponding to the MIC.

On wood, significantly higher concentrations of MBT were required to control fungal growth than in liquid culture $(\mathrm{P}<0.05)$, irrespective of the test fungus used. The highest degree of tolerance was again observed for T. viride with a MIC in excess of $0.64 \% \mathrm{w} / \mathrm{v}$ of MBT (Table 2). The MBT concentration was not quantified at the faces of wafers after treatment; therefore, MIC values reported herein reflect the concentration of MBT in the treatment solution required controlling fungal growth on wood.

TABLE 2: Range of minimum inhibitory concentrations of MBT towards test fungi in liquid culture and on radiata pine.

\begin{tabular}{lcc}
\hline \multirow{2}{*}{ Fungi } & \multicolumn{2}{c}{ MIC of MBT $(\% \mathrm{w} / \mathrm{v})$} \\
\cline { 2 - 3 } & Liquid culture & Radiata pine \\
\hline Ophiostoma floccosum & $0.00002-\leq 0.00004$ & $0.16-\leq 0.32$ \\
Leptographium procerum & $0.00001-\leq 0.00002$ & $0.08-\leq 0.16$ \\
Sphaeropsis sapinea & $0.00002-\leq 0.00004$ & $0.02-\leq 0.04$ \\
Trichoderma viride & $0.0004-\leq 0.0005$ & $0.64-\leq 1.28$ \\
\hline
\end{tabular}

Evaluating the mode of action of MBT against two wood inhabiting fungi

For both experiments, the trends were the same for both fungi. The only difference was a slightly greater tolerance shown by $O$. floccosum to different concentrations of the fungicide, therefore, only $S$. sapinea results are presented.

In Experiment 1, propagules of $S$. sapinea successfully colonised faces $\mathrm{C}$ and D of wafers treated with 0.01 and $0.02 \% \mathrm{w} / \mathrm{v}$ of MBT, giving MSC values between $40-88 \%$ (Fig. 1). For the inoculated wafer (faces A and B), exposure to wafers treated with $0.02 \% \mathrm{w} / \mathrm{v}$ of MBT, yielded a MSC value of approximate $80 \%$ on face A, which was reduced to around $50 \%$ when exposed to $0.04 \% \mathrm{w} / \mathrm{v}$ of MBT. After exposure to wafers treated with $0.08 \% \mathrm{w} / \mathrm{v}$ of MBT, face A had only $10 \%$ fungal growth with no growth evident at higher treatment concentrations. For treated and control sets of assemblies, MSC values were higher on faces A and D than C and B. For example, control wafers had an average MSC of around $80 \%$ on faces A and D and slightly more than $60 \%$ on faces $\mathrm{B}$ and $\mathrm{C}$, with the latter two faces having been in direct contact during incubation.

In Experiment 2, MSC values generally decreased on face A as MBT concentration increased. Colonisation of face A by $S$. sapinea was not observed after indirect exposure to wafers treated with $0.64 \%$ of MBT (Fig. 2). 


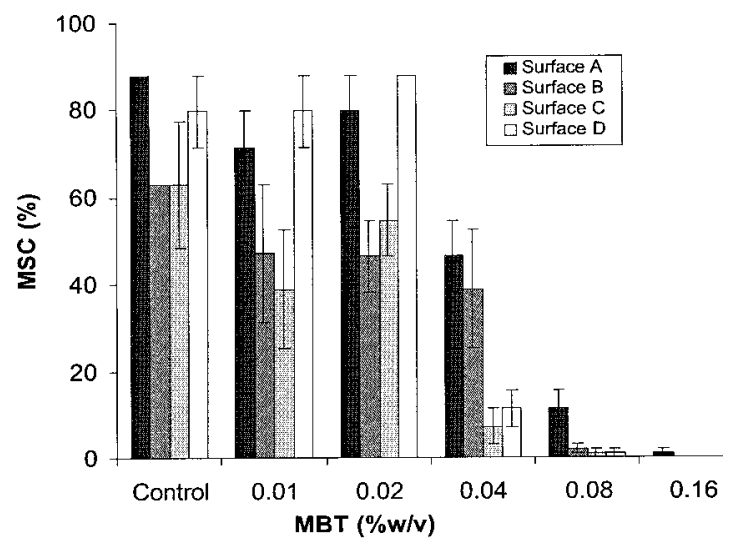

FIGURE 1: Fungal growth on each face of two wafers after 5 weeks incubation. Wafer 1 (faces A-B) was inoculated with $S$. sapinea and wafer 2 (faces C-D) was treated with MBT just prior to assembly. During assembly, inner faces $(B$ and $C)$ were adjacent to each other. $(n=3$, except for control where $n=6$; Bars represent standard error of the mean.)

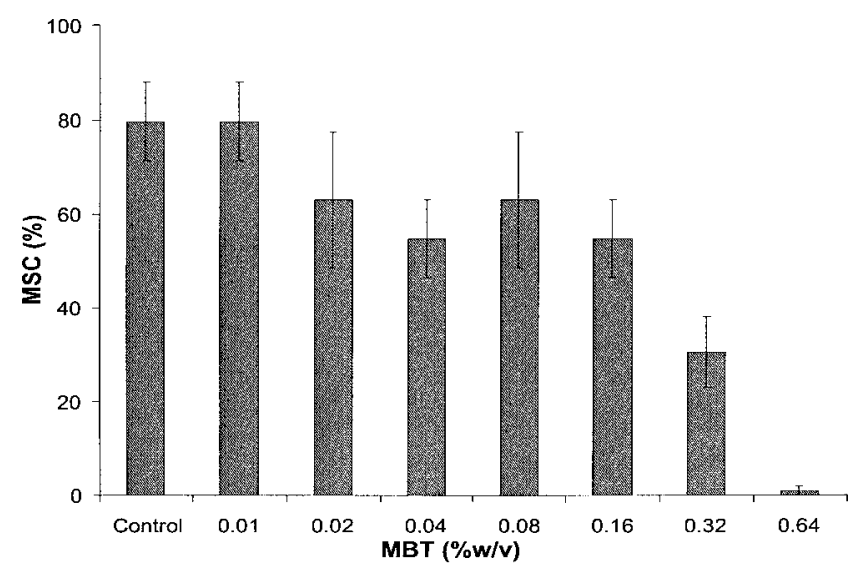

FIGURE 2: Fungal growth determined on face $A$ after 5 weeks of incubation. Wafer 1 (faces A-B) was inoculated with $S$. sapinea and wafer 2 (faces C-D) was treated with MBT. Aluminum foil was placed between faces $B$ and $C$ of the two wafers just prior to assembly. $(n=3$, except for control where $n=6$; Bars represent standard error of the mean.)

\section{DISCUSSION}

The four test fungi were chosen for the study because they are important colonisers of radiata pine in New Zealand causing deterioration of wood (Butcher 1968). In the current study, the four test fungi showed differences in their sensitivity towards MBT. The relatively high tolerance of Trichoderma viride to MBT observed in this study is in agreement with the results of related research (Williams \& Lewis 1989). It is reported that conidia differ widely in their ontogeny (Ballesta \& Villanueva 1971) and this may have influenced their susceptibility to chemical stress. Furthermore, differences in 
tolerance have been reported between different groups of wood inhabiting fungi (mould and staining fungi) and between species and/or strains within the same fungal genera (Williams \& Lewis 1989; Eden et al. 1999a).

In this study, higher treatment concentrations of MBT were required to control fungal growth on wood than in liquid culture. It is well known that after dip-treatment, a dilution effect occurs on fresh wood, which contains free water. This results in lower concentrations of the fungicide at the surface than in the original treatment solution. Also, MBT immediately penetrates and continues to diffuse into the sub-surface regions of wood (Eden et al. 1999b) thus contributing to a further dilution of MBT at the wood surface. Therefore, the MIC values presented here to control fungal growth on wood only refer to the MBT concentration of the treatment solution.

In Experiment 1, for treated and control sets of wood wafer assemblies, fungal growth was more prolific on faces A and D compared to B and C. This observation suggests that the interface of $\mathrm{BC}$ (in direct contact) had less favourable environmental conditions for fungal growth, such as higher moisture content and/or reduced oxygen tension.

In Experiment 1, where direct diffusion of MBT occurred, growth of S. sapinea was not observed on untreated wafers after exposure to wafers treated with MBT in excess of $0.16 \%$. In contrast, in Experiment 2, where aluminum foil was placed between wafers to prevent direct diffusion of MBT from the treated into the untreated wafer, the growth of $S$. sapinea on face A (untreated) was inhibited only after exposure to the highest concentration $(0.64 \%)$ of MBT used. This observation suggests that the direct diffusion of MBT through both liquid and vapour phases, was the main inhibitory effect and vapour diffusion of any other, as yet unidentified, volatiles was a secondary. In the current study, MBT vapour and potential volatile(s) that were derived from MBT treated wafers, were not analysed chemically but are presently being investigated.

\section{REFERENCES}

Ballesta, J.P.G.; Villanueva, J.R. 1971: Cell wall components of various species of yeasts. Trans. Brit. Mycol. Soc. 56: 403-410.

Butcher, J.A. 1968: The ecology of fungi infecting untreated sapwood of Pinus radiata. Can. J. Bot. 46: 1577-1589.

Eden, D.; Kreber, B.; Chittenden, C.; Wakeling, R. 1999a: Variable susceptibility of common sapstain fungi against commercial antisapstain products. Material Und Organismen 36(1): 1-12.

Eden, D.; Singh, T.; Kreber, B. 1999b: Effect of mobile fungicides on fungal pre-infection in radiata pine. Document No. IRG/WP/30191. The International Research Group on Wood Preservatives. Stockholm, Sweden.

Eden, D.; Wakeling, R.N.; Chittenden, C.; Van der Waals, J.G.; Carpenter, B.E. 1997: Time limits for holding logs to achieve successful antisapstain treatment. In: Kreber, B. ed. Strategies of improving protection of logs and lumber. Forest Research Institute Bulletin No. 204. Pp. 55-61.

Hedley, M.E.; Preston, A.F.; Cross, D.J.; Butcher, J.A. 1979: Screening of selected agricultural and industrial chemicals as wood preservatives. Int. Biodeter. \& Biodegrada. 15: 9-18.

Wakeling, R.N.; Eden, D.R.; Kreber, B; Chittenden, C.; Van der Waals, J.G.; Carpenter, B.E.; Dorset, I.; Price, A. 2000: Recent advances in protection of unseasoned radiata pine wood in New Zealand. Int. Biodeter. \& Biodegrada. 46: 83-88.

Williams, G.R.; Lewis, D.A. 1989: Observation on colonisation of freshly-felled timber treated with prophylactic chemicals by mould and sapstain fungi. Document IRG/ WP/1394. The International Research Group on Wood Preservatives. Stockholm, Sweden.

Williams, G.R.; Eaton, R.A.; Lewis, D.A. 1985: Observation on the penetration of preservative into green timber. Document IRG/WP/3335. The International Research Group on Wood Preservatives. Stockholm, Sweden. 